\title{
Multidrug resistance gene 1 polymorphisms in pediatric patients with leukemia at a national referral hospital in Indonesia
}

\author{
Rina Mutiara ${ }^{a}$, Bernadius Agustinus ${ }^{\mathrm{b}}$, Christian Badia Sitompul ${ }^{\mathrm{b}}$, Amarila Malik ${ }^{\mathrm{b}}$, Djajadiman Gatot ${ }^{\mathrm{c}}$, \\ Frans D. Suyatna ${ }^{\mathrm{d}}$ \\ ${ }^{a}$ Graduate School of Biomedicine, Faculty of Medicine, Universitas Indonesia, Kampus UI Salemba, \\ Jakarta 10430, Indonesia \\ ${ }^{b}$ Pharmaceutical Biotechnology Division, Faculty of Pharmacy, Universitas Indonesia, Kampus UI \\ Depok, Depok 16424, Indonesia \\ ${ }^{c}$ Cipto Mangunkusumo Hospital, Jakarta 10320, Indonesia \\ ${ }^{d}$ Faculty of Medicine, Universitas Indonesia, Kampus UI Salemba, Jakarta 10430, Indonesia
}

\begin{abstract}
Background: Acute lymphoblastic leukemia (ALL) is the most prevalent cancer in the pediatric population. From $25 \%$ to $30 \%$ of patients with ALL will have a relapse that leads to death when they are teenagers. At Cipto Mangunkusumo Hospital, 40\% of 126 pediatric patients with ALL relapsed from 2005 to 2011. A multiple variant of multidrug resistance gene 1 (MDR1) is C3435T, which can be used to understand the genetic basis of susceptibility to relapse.

Objectives: To identify the profile of MDR1 polymorphism in pediatric Indonesian patients with ALL.

Methods: We collected data from 44 patients with ALL who attended Cipto Mangunkusumo Hospital between January and June 2014. We investigated a silent C3435T polymorphism in MDR1 exon 26 with polymerase chain reaction- restriction fragment length polymorphism using MboI.

Results: There were 32 male and 12 female patient participants in this study. Eighteen patients were 1-3 years old and 26 were over 3 years. The mean age at $1-3$ years was $2.4 \pm 0.86$, and over 3 years it was $6.3 \pm 2.67$ years. There were 27 patients with ALL in the standard risk group and 17 in the high risk group. We determined that the 25 samples from patients with ALL in the standard risk group were not digestible (allele T) and the 6 samples from patients with ALL in the high risk group were digestible (allele C).

Conclusions: The prevalence of the $\mathrm{T}$ allele was higher than that of the $\mathrm{C}$ allele in pediatric Indonesian patients with ALL.
\end{abstract}

Keywords: Acute lymphoblastic leukemia, ALL, polymorphism, MDR1 gene, P-glycoprotein (P-gP), PCR RFLP

According to the World Health Organization (WHO), cancer is the second most frequent cause of death in developing countries. There is estimated annual incidence of 100 new cancer cases per 100,000 population in Indonesia, and 4,100 of these cases are likely to be in children [1]. The American Cancer Society reported that in 2009 there were 10,730 new cancer cases in the pediatric age group $0-14$ years old. An estimated 1,380 deaths were reported for pediatric patients aged $0-14$ years old in 2009

Correspondence to: Frans D. Suyatna, Faculty of Medicine, Universitas Indonesia, Kampus UI Salemba, Jalan Salemba Raya no. 4, Jakarta 10430, Indonesia. E-mail: franciscus.suyatna@ ui.ac.id as caused by cancer, one third of which were caused by leukemia [2]. The most common malignancy in the pediatric population worldwide is acute lymphoblastic leukemia (ALL). ALL is a heterogeneous group of leukemias that result from the clonal proliferation of cancerous lymphoblasts in bone marrow, and in secondary lymphoid organs. Children 1-10 years old are at particular risk of developing ALL. The overall cure rate is approximately $80 \%$ [3].

The Indonesian Paediatric Oncology Foundation stated that $2 \%-3 \%$ cancer cases in Indonesia occur in children [4]. Based on Cipto Mangunkusumo Hospital data from 2000-2006, there were 973 pediatric inpatients with cancer, and $27 \%$ of them 
died [5]. The frequency of ALL relapses in Indonesia remains high at approximately $40 \%$ [5]. Data from two Indonesian teaching hospitals indicated that 22\% of patients have relapses [6].

Gene polymorphisms play an important role in the survival rate of patients with ALL. The transport of substrates across cell membranes is mediated by transmembrane proteins known as ATP-binding cassette (ABC) transporters [7]. ABC transporters excrete substances out of the cell, bring drugs across membranes and transport lipids. Mutations in the multidrug resistance gene 1 (MDR1) have been shown to be associated with human disease [3]. P-glycoprotein (P-gp) is a product of MDR1, and has a key role in the transport of xenobiotics, steroid breakdown, and the excretion of metabolites, carcinogens, and cytotoxic drugs such as vinca alkaloids, taxanes, anthracyclines, and epipodophyllotoxins from cells [7].

Complex treatment regimens have been developed for patients with ALL. These treatment programs comprise induction chemotherapy to decrease the numbers of lymphoblasts in the bone marrow, and to reestablish normal hematopoietic function, consolidation therapy to abolish remaining malignant cells, and maintenance chemotherapy to avert relapse. Current treatment choices include medication with (1) thiopurine antimetabolites, including mercaptopurine and thioguanine; (2) consolidation therapy including high-dose methotrexate and continuation therapy including low-dose methotrexate; (3) synthetic glucocorticoids, including dexamethasone and prednisolone, which cause apoptosis and G1 cell-cycle arrest, and (4) L-asparaginase [8].

Specific inherited polymorphisms are correlated with drug toxicity in leukemia. The ABC family of transporters is composed of three main proteins: (1) P-gp, the product of MDR1 also known as the gene for adenosine triphosphate-binding cassette subfamily B transporter-1 (ABCB1), (2) multidrug resistance associated protein 1 , and (3) breast cancer resistance protein [9].

Twenty-eight single nucleotide polymorphisms (SNPs) of MDR1 are recognized. A silent polymorphism is associated with P-gp expression [10] and comprises a $\mathrm{C}$ to $\mathrm{T}$ exchange at position 3435 (C3435T) in exon 26 of the MDR1, which is the most common MDR1 polymorphism [11]. People with the 3435TT genotype have significantly lower level of
MDR1 expression and function than those with the 3435CC genotype. It is hypothesized that reduced P-gp expression can cause accumulation of xenobiotics and toxic compounds in cells, which can predispose affected individuals to cancer and other diseases [12]. Analysis of the C3435T polymorphism of MDR1 in Han Chinese showed that development of pediatric ALL is associated with the TT genotype, and a poor prognosis is associated with the CC genotype [3]. The clinical outcome of pediatric patients with ALL can be affected by their genetic variability.

In the present study, we identified the profile of MDR1 polymorphism in pediatric patients with ALL. These data will be used to determine the treatment protocol for our patients with ALL and could help to identify patients with a high risk of relapse and predict therapy outcome.

\section{Materials and methods \\ Patients}

We collected peripheral blood samples from 44 pediatric patients with ALL at the Paediatric Haematology-Oncology Clinic of Cipto Mangunkusumo Hospital between February and May 2014. Patients were treated according to the ALL Indonesian Protocol 2006, and treatment based on this protocol and this study was approved by the Human Research Ethics Committee of the Faculty of Medicine Universitas Indonesia (No. 35/H2.F1/ETIK/2014). A control group consisted of volunteers who had been admitted to Cipto Mangunkusumo Hospital. The written informed consent was provided by the parents or legal guardians of all participants.

\section{Genotyping of MDR1 SNPs}

We collected whole blood from the enrolled participants, and performed genotyping of patients with ALL and healthy controls by polymerase chain reaction-restriction fragment length polymorphism (PCR-RFLP). We isolated DNA from peripheral blood cells using a standard salting-out protocol and used gel electrophoresis of DNA isolates to determine their quality. The C3435T variant of the MDR1 was identified with the forward primer 5'-GAGCCCATC CTGTTTGACTGC-3' and 5'-TGTATGTTGGCCTC CTTTGCTG- $3^{\prime}$ as the reverse primer, yielding a 206 base pair (bp) product. The primer design was determined from the published sequences for genotyping MDR1 polymorphisms using genomic DNA. For PCR reactions, 200 ng of genomic DNA 
was amplified in $25 \mu \mathrm{L}$ of reaction mixture containing $4 \mu \mathrm{M}$ of each dNTP (dATP, dCTP, dGTP, and dTTP), 20 pmol of each primer, $0.875 \mathrm{mM} \mathrm{MgSO}_{4}$ and $0.7 \mathrm{U}$ DNA polymerase from Thermococcus kodakaraensis KOD1. PCR amplification was effected by an initial 4 min denaturation at $95^{\circ} \mathrm{C}$, followed by 30 cycles of denaturation at $95^{\circ} \mathrm{C}$ for $30 \mathrm{~s}$, annealing at $60^{\circ} \mathrm{C}$ for $30 \mathrm{~s}$, and extension at $72^{\circ} \mathrm{C}$ for $1 \mathrm{~min}$. The terminal extension was performed at $72^{\circ} \mathrm{C}$ for $7 \mathrm{~min}$. Amplified DNA fragments (206 bp) were digested by MboI (Fermentas; Thermo Fisher Scientific, Waltham, MA USA) for $3 \mathrm{~h}$ at $37^{\circ} \mathrm{C}$ followed by enzyme inactivation for 20 minutes at $65^{\circ} \mathrm{C}$. The PCR product was identified in a $2 \%(\mathrm{w} / \mathrm{v})$ agarose gel stained with ethidium bromide and visualized directly under UV light.

\section{Treatment regimen}

Children with ALL who visited our Paediatric Haematology-Oncology Clinic were classified into standard or high-risk groups and treated using the ALL Indonesian Protocol 2006. Age, sex, and risk group were all used as patient characteristics as shown in Table 1. We performed chemotherapy regularly according to the treatment regimen. The patients have routine blood tests at the designated intervals. After finishing the ALL protocol, therapy is continued with follow-up every 3 months for the 1st year, every 6 months for the 2nd and 3rd years, and each year thereafter for 3 years. We perform routine blood tests at every follow-up visit, and we examine bone marrow aspirates to determine whether or not the patients are in remission. During the follow-up visits, liver and kidney function tests, echocardiography, and abdominal ultrasonography are performed routinely.

\section{Results}

This study consisted of 44 patients (1-18 years old) with ALL and 9 healthy individuals as a control group. Their demographic characteristics are presented in Table 1.

DNA fragments of MDR1 exon 26 that covered the SNP (nucleotide position 176) were amplified. The primer design was determined from data published from the study of Zhai et al., which produced a 110 bp DNA fragment to identify the C3435T polymorphism [3].

In vitro DNA amplification of MDR1 using specific primers produced a 110 bp DNA product (Figure 1).

Digestion of the amplified fragment (amplicon) with $M b o$ I resulted in 110 base pair (bp) DNA fragment ( $\mathrm{T}$ allele) or $81 \mathrm{bp}$ fragment (C allele). We found the $\mathrm{T}$ allele was significantly associated with the occurrence of ALL (84\% of patients with ALL compared with $44 \%$ of healthy subjects). The $C$ allele was found in children with high-risk leukemia associated with poor prognosis. The PCR product of the $\mathrm{T}$ allele is not digestible by the $\mathrm{MboI}$ restriction endonuclease, but the product from the $\mathrm{C}$ allele is digestible [7]. Examples of digestible and indigestible DNA are shown in Figure 2.

We identified the frequency of the $\mathrm{C}$ and $\mathrm{T}$ alleles as shown in Table 2.

There were more patients in the standard group than in the high-risk group. Genotyping of the C3435T MDR1 SNP by RFLP was successful.

Table 1. Baseline patient characteristics

\begin{tabular}{ll}
\hline Variable & $\mathbf{n}=\mathbf{4 4}$ \\
\hline Age (year) & \\
1-3 years & $2.4 \pm 0.86$ \\
$\quad$ 3 years & $6.3 \pm 2.67$ \\
Age category & \\
$\quad$ 1-3 years & $18(41 \%)$ \\
>3 years & $26(59 \%)$ \\
Sex & \\
Male & $32(73 \%)$ \\
Female & $12(27 \%)$ \\
Risk group & \\
Standard & $27(61 \%)$ \\
High & $17(39 \%)$ \\
\hline
\end{tabular}

mean \pm standard deviation 


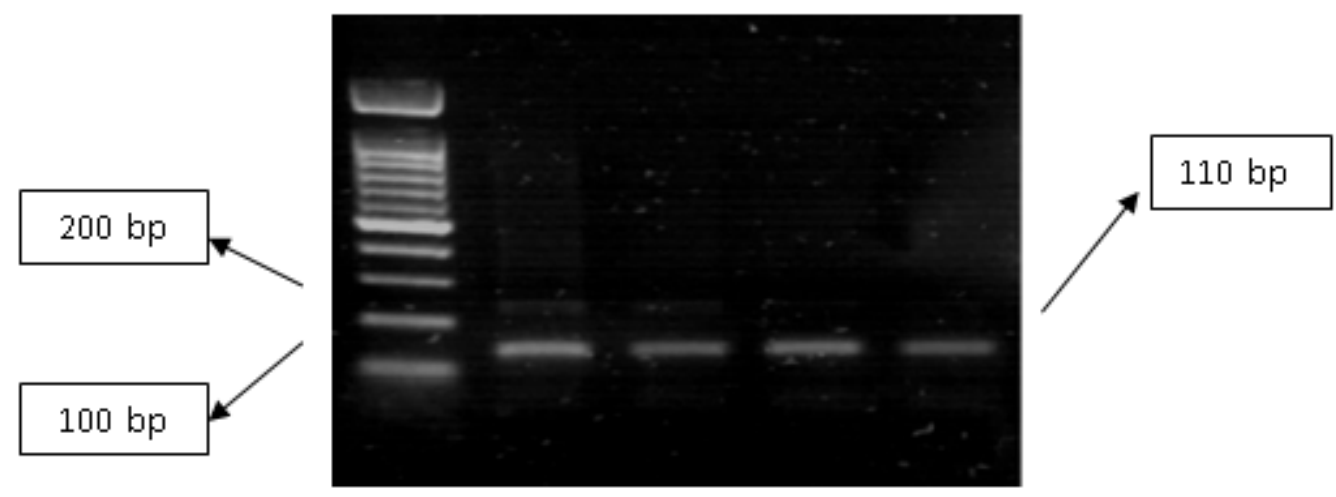

Figure 1. DNA bands from PCR amplification

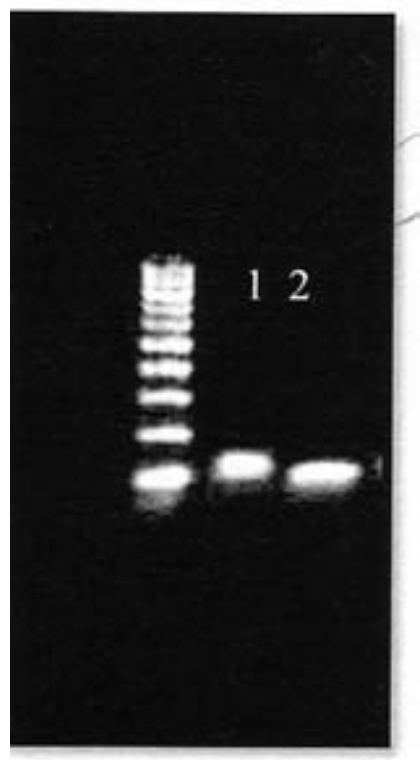

Figure 2. Comparison of the DNA digestion results. Number 1 is indigestible DNA (110) with a GATT sequence at the restriction site (allele T), and number 2 is digestible DNA (81 bp) with a GATC sequence at the restriction site (allele C).

Table 2. Frequency of alleles in ALL patients and healthy subjects in the MDR1 study

\begin{tabular}{lll}
\hline & ALL patients & Healthy subjects \\
\hline T allele & & \\
$\quad$ Standard risk & $25(57 \%)$ & $4(44 \%)$ \\
High risk & $12(27 \%)$ & \\
C allele & & $5(56 \%)$ \\
$\quad$ Standard risk & $1(2 \%)$ & \\
High risk & $6(14 \%)$ & \\
\hline
\end{tabular}




\section{Discussion}

Cancer drug resistance can cause treatment failures [13]. The mutation and amplification of drug targets leads to multidrug resistance [14]. The clinical response of patients with ALL to chemotherapy is related to the incidence of ALL relapse [15]. Individualized chemotherapy is intended to optimize its efficacy and decrease the toxicity of the treatment. ALL is a frequent target of pharmacogenetic drug design [16]. The MDR1 is also known as ABCB1 [17]. SNPs have been identified in MDR1, and the C3435T polymorphism in exon 26 is associated with the expression and function of P-gp. Carriers of the T-allele have lower expression and function of P-gp compared with wild-type CC homozygotes [18]. A prognostic role of C3435T MDR1 SNP was reported for childhood ALL, but its utility in pediatric Indonesian patients has not been investigated. The evidence of relapse in the Indonesian population is high. Therefore, there is good reason to evaluate the significance of this polymorphism that affects the prognosis of pediatric ALL in Indonesia. To our knowledge, this is the first investigation of the effect of the C3435T multiple drug resistance SNP in pediatric patients with ALL in Indonesia. Although chemotherapy arrests as much as $80 \%$ of childhood ALL, almost $25 \%$ of cured children will relapse [19].

The multiple drugs used to treat acute leukemia can induce over expression of P-gp and result in resistance [20]. The ABC transporter family contains a number of proteins that can mediate multidrug resistance, and this resistance remains an important challenge in the treatment of acute leukemia. MDR1 polymorphisms are considered to affect the level of expression of P-gp, thereby affecting the development of ALL. The C3435T polymorphism in MDR1 exon 26 may cause an abnormal P-gp protein conformation and P-gp substrate-binding inhibition. In children with ALL, the frequency of the TT genotype of the MDR1 C3435T polymorphism appears significantly higher than in controls, while MDR1 3435CC polymorphism appears significantly associated with poor prognosis of pediatric Taiwanese patients with ALL after the TPOGALL-93-SR treatment protocol [21]. The high incidence of relapse means that the development of individual therapy for ALL is very important. The genetic profile of a patient can be used to ensure a favorable response to chemotherapy. Differences in study design have been attributed to differences in the data reported by various studies. The various data may also be attributed to genetic variations in the various populations of patients with ALL.

The biggest limitation of this study is its small sample size. Future studies should enrol more patients. The SNP profile can affect P-gp expression or the severity of disease and response to chemotherapy. The data could be used to design a therapy regimen for patients with ALL. Patients with ALL and the MDR1 3435 CC genotype may eliminate P-gp substrates including vincristine, mitoxantrone, anthracyclines, and daunorubicin more efficiently, resulting in a poor prognosis. Study of the association between these SNPs, the risk of ALL, and clinical outcome in various populations with different ethnicities is warranted.

\section{Conclusions}

We identified the MDR1 profile of pediatric patients with ALL at a national referral hospital in Indonesia. The prevalence of the $\mathrm{T}$ allele was higher than that of the $C$ allele in pediatric Indonesian patients with ALL. Multiple drug resistance SNPs provide potential biomarkers for screening for patients with a high risk of ALL and knowledge of their profiles could improve their clinical management by predicting their vulnerability and clinical outcome, thus improving their prognosis.

\section{Acknowledgments}

This study was approved and supported by funding from Hibah Penelitian Multidisiplin Universitas Indonesia in 2014.

\section{Conflict of interest statement}

The authors have no conflict of interest to declare.

\section{References}

1. Pirard P, Stiller C. World Health Organization Europe. Incidence of childhood leukaemia. Standardized incidence rate of leukemia as defined by ICD-10 codes C90-95 in children aged 0 to 14 years. European Environment and Health Information System. Fact sheet 4.1. Code: RPG4_Rad_E1. Copenhagen: WHO Regional Office for Europe, 2009.

2. American Cancer Society. Cancer facts \& figures 2009. Atlanta: American Cancer Society; 2009.

3. Zhai X, Wang H, Zhu X, Miao H, Qian X, Li J, et al. Gene polymorphisms of ABC transporters are associated with clinical outcomes in children with acute lymphoblastic leukemia. Arch Med Sci. 2012; 8: 
659-71.

4. Simanjorang C, Adisasmita AC, Tehuteru ES. [Epidemiological picture of child leukemia cases in the cancer hospital "Dharmais", 2004-2008] Indonesian J Cancer. 2010; 4:15-22. [In Indonesian, English abstract]

5. Bangun M. [Analysis of risk factors of relapse in children with leukemia in Cipto Mangunkusumo Hospital, Jakarta]. Master of Nursing thesis, University of Indonesia, 2012. [In Indonesian, English abstract]

6. Mostert S, Sitaresmi MN, Veerman A. Influence of socioeconomic status on childhood acute lymphoblastic leukemia treatment in Indonesia. Am Acad Pediatr. 2006; 1600-6.

7. Rao DN, Anuradha C, Vishnupriya S, Sailaja K, Surekha D. Association of an MDR1 gene (C3435T) polymorphism with acute leukemia in India. Asian Pacific J Cancer Prev. 2010; 11:1063-6.

8. Pui C, Mullighan CG, Evans WE, Relling MV. Pediatric acute lymphoblastic leukemia/ : where are we going and how do we get there? Blood. 2012; 120:1-3.

9. Tafuri A, Gregorj C, Petrucci MT, Ricciardi MR, Mancini M, Cimino G, et al. MDR1 protein expression is an independent predictor of complete remission in newly diagnosed adult acute lymphoblastic leukemia. Blood. 2014; 100:974-82.

10. Hoffmeyer S, Burk O, von Richter O, Arnold HP, Brockmoller J, Johne A, et al. Functional polymorphisms of the human multidrug-resistance gene: Multiple sequence variations and correlation of one allele with P-glycoprotein expression and activity in vivo. Proc Natl Acad Sci USA. 2000; 97:3473-8.

11. Wu D, Zhang J, Li J, Dong W. Lack of association of the MDR1 C3435T polymorphism with susceptibility to gastric cancer and peptic ulcer: a systemic review and meta-analysis. Asian Pacific J Cancer Prev. 2014; 15:3021-7.

12. Miladpour B, Shokouhi A, Heravi RE, Banihashem A, Esmaeili $\mathrm{H}$, et al. Association of acute lymphoblastic leukemia and MDR1 gene polymorphism in an ethnic
Iranian population. Iran J Blood Cancer. 2009; 1:63-7.

13. Chen S, Yang C, Jaing T, Hung I, Shih L, Ho P, et al. Clinical impact of in vitro cellular drug resistance on childhood acute lymphoblastic leukemia in Taiwan. Leuk Lymphoma. 2012; 53:1536-42.

14. Zahreddine H, Borden KLB. Mechanisms and insights into drug resistance in cancer. Front Pharmacol. 2013; 4:1-8.

15. Klumper BE, Pieters R, Veerman AJP, Huismans DR, Loonen $\mathrm{AH}$, et al. In vitro cellular drug resistance in children with relapsed/refractory acute lymphoblastic leukemia. Blood. 1995; 86:3861-8.

16. Erdelyi DJ, Kamory E, Zalka A, Semsei AF, Csokay B, Andrikovics $\mathrm{H}$, et al. The role of ABC-transporter gene polymorphisms in chemotherapy induced immunosuppression, a retrospective study in childhood acute lymphoblastic leukaemia. Cell Immunol. 2006; 244:121-4.

17. Svirnovski A, Shman TV, Serhiyenka TF, Savitski VP, Smolnikova VV, Fedasenka. ABCB1 and ABCG2 proteins, their functional activity and gene expression in concert with drug sensitivity of leukemia cells. Hematology. 2009; 14:204-12.

18. Wang L, Song YB, Zheng WL, Jiang L, Ma WL. Association between polymorphisms in the MDR1 gene and risk of cancer: a systematic review and pooled analysis of 52 case-control studies. Cancer Cell Int. 2013; 13-46.

19. Valera ET, Scrideli CA, Queiroz RG, Mori BM TL. Multiple drug resistance protein (MDR1), multidrug resistance-related protein (MRP) and lung resistance protein (LRP) gene expression in childhood acute lymphoblastic leukemia. Sao Paulo Med J. 2004; 122: 166-71.

20. Xia CQ, Smith PG, Pharmaceuticals M. July Drug efflux transporters and multidrug resistance in acute leukemia. Mol Pharmacol Fast Forw. 2012;1-50.

21. Yang YL, Lin DT, Chang SK, Lin SR, Lin SW, Chiou RJ, et al. Pharmacogenomic variations in treatment protocols for childhood acute lymphoblastic leukemia. Pediatr Blood Cancer. 2010; 54:206-11. 